\title{
Visual scanning preferences in low birth weight preterm infants
}

\author{
Preferências de rastreamento visual em prematuros nascidos com baixo peso
}

\author{
Vivian R. G. Lederman, ${ }^{1}$ (D) Ana L. Goulart, ${ }^{2}$ Juliana G. Negrão, ${ }^{1}$ Deyse H. F. da Cunha, ${ }^{2}$ \\ Amélia M. N. dos Santos, ${ }^{2}$ José S. Schwartzman ${ }^{1}$
}

\begin{abstract}
Introduction: Few studies have used eye tracking as a screening tool for autism spectrum disorder (ASD) in preterm infants.

Objectives: To evaluate fixation time on social and non-social figures and percentage of preterm babies who gazed at the images.

Methods: This was a cross-sectional study of 31 preterm infants born weighing $\leq 2,000 \mathrm{~g}$ in which eye gaze was evaluated at 6 months of corrected age. Six boards with social and non-social figures were projected on a computer screen, successively, evaluating time and percentage of preterm babies who gazed at each board. The Modified Checklist for Autism in Toddlers (M-CHAT) was answered at 18 months of corrected age.

Results: Preterm infants showed longer visual fixation time on social figures compared with non-social images, regardless of the position of the social figure on the board. Similar percentages of preterm infants gazed either at social or non-social figures, at social figures with a direct or an indirect look, and at the eyes or mouth of the social figures. No preterm infant screened positive on the M-CHAT.

Conclusion: At 6 months of corrected age, preterm infants show the ability to gaze in an eye-tracking test, with preference for social figures, suggesting that this tool could be useful as another screening instrument for ASD.
\end{abstract}

Keywords: Autism, autism spectrum disorder, eye tracking, preterm infant, social visual engagement.

\section{Resumo}

Introdução: Poucos estudos utilizaram a varredura visual como ferramenta para rastreamento de transtorno do espectro do autismo (TEA) em bebês prematuros.

Objetivos: Avaliar bebês prematuros quanto ao o tempo de fixação de olhar em figuras sociais e não sociais e a porcentagem deles que olharam para as imagens.

Métodos: Este estudo transversal incluiu 31 bebês prematuros com $\leq 2.000 \mathrm{~g}$ ao nascer, cujo rastreamento visual foi avaliado aos 6 meses de idade corrigida. Seis pranchas com figuras sociais e não sociais foram projetadas em tela de computador, sucessivamente, avaliando-se o tempo e porcentagem de prematuros que olharam para cada prancha. O Modified Checklist for Autism in Toddlers (M-CHAT) foi respondido aos 18 meses de idade corrigida.

Resultados: Os bebês prematuros apresentaram maior tempo de fixação visual em figuras sociais do que não sociais, independentemente da posição da figura social na prancha. Porcentagens similares de prematuros olharam tanto para figuras sociais como para não sociais, para figuras sociais com olhar direto ou indireto, e para boca ou olhos das figuras sociais. Nenhum prematuro foi rastreado positivamente pelo M-CHAT.

Conclusão: Aos 6 meses de idade corrigida, prematuros apresentaram habilidade para varredura em teste de rastreamento visual, com preferência por figuras sociais, sugerindo que esta ferramenta pode ser útil como mais um instrumento para rastreamento de TEA.

Descritores: Autismo, transtorno do espectro do autismo, varredura visual, prematuro, engajamento social visual.

\footnotetext{
${ }_{1}$ Programa de Pós-Graduação em Distúrbios do Desenvolvimento, Universidade Presbiteriana Mackenzie, São Paulo, SP, Brazil. ${ }^{2}$ Departamento de Pediatria, Universidade Federal de São Paulo - Escola Paulista de Medicina (UNIFESP-EPM), São Paulo, SP, Brazil.

This work was developed by researches from Universidade Presbiteriana Mackenzie and Universidade Federal de São Paulo at the Preterm Clinic of Universidade Federal de São Paulo - Escola Paulista de Medicina.

Submitted Oct 01 2018, accepted for publication Mar 022019.

Suggested citation: Lederman VRG, Goulart AL, Negrão JG, da Cunha DHF, dos Santos AMN, Schwartzman JS. Visual scanning preferences in low birth weight preterm infants. Trends Psychiatry Psychother. 2019;41(4):334-339. http://dx.doi.org/10.1590/2237-6089-2018-0083
} 


\section{Introduction}

With the improvement of survival rates of smaller and more immature preterm infants, the presence of injuries poses a major challenge for public health services. ${ }^{1}$ Between 15 and $45 \%$ of preterm infants present perceptual, cognitive and motor skill impairments. ${ }^{2}$ Although detection can be difficult in the early years, the manifestation of problems in social communication, emotional attachment and joint attention - all signs compatible with autism spectrum disorder (ASD) - is frequent in preterm infants. ${ }^{3}$ Whether or not a diagnosis of ASD is established, the prompt identification of development delays permits early intervention and condition improvement. ${ }^{4}$

The American Academy of Pediatrics (AAP) recommends ASD screening at 18-24 months with the Modified Checklist for Autism in Toddlers (M-CHAT), although some signs of ASD may be observed even earlier. Instruments such as eye tracking have become an important tool to screen for early signs of ASD.

Typical newborns show visual preferences for social stimuli from their very first days of life. ${ }^{5}$ Conversely, fullterm children who are later diagnosed with ASD show eye-gaze decline when seeing social figures between 2 and 6 months of age, which does not occur in typical term children. The lack of interest in social figures could be a sign of social impairment and may be identified in the first few months of the child's life through eye tracking. ${ }^{6}$ Preliminary visual scanning studies with preterm infants seem to indicate similar behaviors to those observed in term children, as preterm babies who have difficulties in social eye gaze may also present difficulties in social interaction and later a diagnosis of ASD. ${ }^{7}$

Nevertheless, visual scanning studies of preterm infants are still limited, and contributions are relevant to establish their typical eye-gaze pattern, aiming for the identification of early impairments. In this sense, the objective of this study was to assess whether preterm infants show the ability to gaze at social and non-social figures at 6 months of corrected age, determining the percentage of preterm babies who gazed at the images and the time lapse of eye gaze.

\section{Methods}

\section{Participants}

A cross-sectional study was conducted with a convenience sample of toddlers born prematurely with low birth weight. The inclusion criteria were: toddlers with 6 months of corrected age, of both sexes, born before 37 weeks' gestation, and with a birth weight $\leq$ $2,000 \mathrm{~g}$, followed at a multidisciplinary outpatient clinic for preterm infants at Universidade Federal de São Paulo (UNIFESP), São Paulo, SP, Brazil. The exclusion criteria were: presence of a genetic syndrome and/or a major motor, visual, or hearing deficiency, according to the diagnoses recorded on the children's charts by the multiprofessional team that accompanied the children after their discharge from the neonatal unit. Preterm infants eligible for the study were selected from a clinical database of children attending that outpatient clinic, according to the inclusion and exclusion criteria established for this study.

This study was conducted after approval by the ethics committees of Universidade Presbiteriana Mackenzie (protocol \#857.269) and UNIFESP (protocol \#936.192), and after all parents or guardians signed a consent form.

\section{Instruments}

Preterm infants were evaluated for eye-tracking using the Mirametrix S2 Eye Tracker version 2.0.0.057 (Mirametrix Research Inc., Montreal, Canada), the Mirametrix Viewer software (made in Canada) and a 17-inch monitor. Six different boards were projected on the computer screen (Figure 1).

\section{Procedure}

An eye-tracking test was performed in preterm babies at 6 months of corrected age, plus or minus 15 days. To perform the evaluation, the preterm infants were positioned in front of the computer, on the lap of a blindfolded parent or guardian, in a dark room and isolated from external stimuli. After calibration, six boards were projected, for five seconds each, always in the same sequence (Figure 1). Boards 1, 2 and 3 contained a social and a non-social figure each, with inverted positions on each board. Boards 4 and 6 contained only social figures: one face with a direct and one with an indirect look. The position of the faces was inverted on each board: board 4 displayed the direct look on the left side, and board 6 the direct look on the right side. Board 5 highlighted only one face, eyes and mouth.

For each board, the software recorded the position and duration of the preterm infant's eye gaze. Only one session was performed, always in the presence of parents or guardians. A single trained researcher extracted the data from the equipment.

\section{Clinical data}

Socioeconomic data, details of the clinical evolution during the hospitalization period in the neonatal 
intensive care unit, and perinatal clinical data were collected from the charts, as follows: mother's age at time of birth, clinical and obstetrical intercurrences during pregnancy, use of prenatal corticosteroids, delivery type, sex, birth weight, gestational age, weight adequacy for gestational age according to the Olsen curve, ${ }^{8}$ Apgar score at first and fifth minutes, presence of respiratory distress syndrome, oxygen dependence at 28 days, arterial canal persistence, peri-intraventricular hemorrhage, periventricular leukomalacia, neonatal sepsis, retinopathy of prematurity, mechanical ventilation and days of hospitalization in the neonatal intensive care unit. Data about other hospitalizations were also collected, as well as information about siblings with an ASD diagnosis.

Screening for ASD signs was performed at 18 months of corrected age, using the M-CHAT.9,10 The $\mathrm{M}-\mathrm{CHAT}$ is an ASD screening instrument designed for use in children between 16 and 30 months of age, with a sensitivity of 0.85 and a specificity of 0.93 . It consists of 23 questions for the child's parents or guardians to answer. Each M-CHAT question, if scored, is worth one point. Questions 2, 7, 9, 13, 14 and 15 are considered critical for signs of ASD, and evaluate social aspects and joint attention, such as pointing at objects, imitation and social interest. The other questions also evaluate sensory stimuli, relationship and motor aspects. Children who fail three or more questions, or two critical questions, are labeled as screening positive for ASD signs. ${ }^{10}$

\section{Statistical analysis}

Categorical variables were expressed as absolute and percentage frequencies and were compared using the chi-square test $\left(x^{2}\right)$. Numerical variables were expressed either as means and standard deviations or as medians (1st and 3rd quartile) and minimummaximum. The percentage of preterm infant's eye gaze at social and non-social figures was compared using the Wilcoxon test.

Statistical analysis was performed using the Statistical Package for the Social Sciences (SPSS) version 17. Significance was set at $p<0.05$.

\section{Results}

\section{Sample demographic and clinical characteristics}

The study sample comprised 31 preterm infants with birth weight $\leq 2,000 \mathrm{~g}$, of which 12 (38.7\%) were male.

Mother's age at birth was $28.2 \pm 6.0$ years and $73.9 \%$ belonged to socioeconomic class $\mathrm{C}$ (average income between US $\$ 500$ and 2,000). None of the preterm babies had siblings with an ASD diagnosis.

Regarding maternal gestational background, $90.0 \%$ of the mothers presented for prenatal checkups, with 7.9 \pm 3.7 consultations. The following clinical gestational complications were reported: systemic pregnancyinduced hypertension (38.7\%), urinary tract infection $(29.0 \%)$, and chorioamnionitis $(8.5 \%)$. During
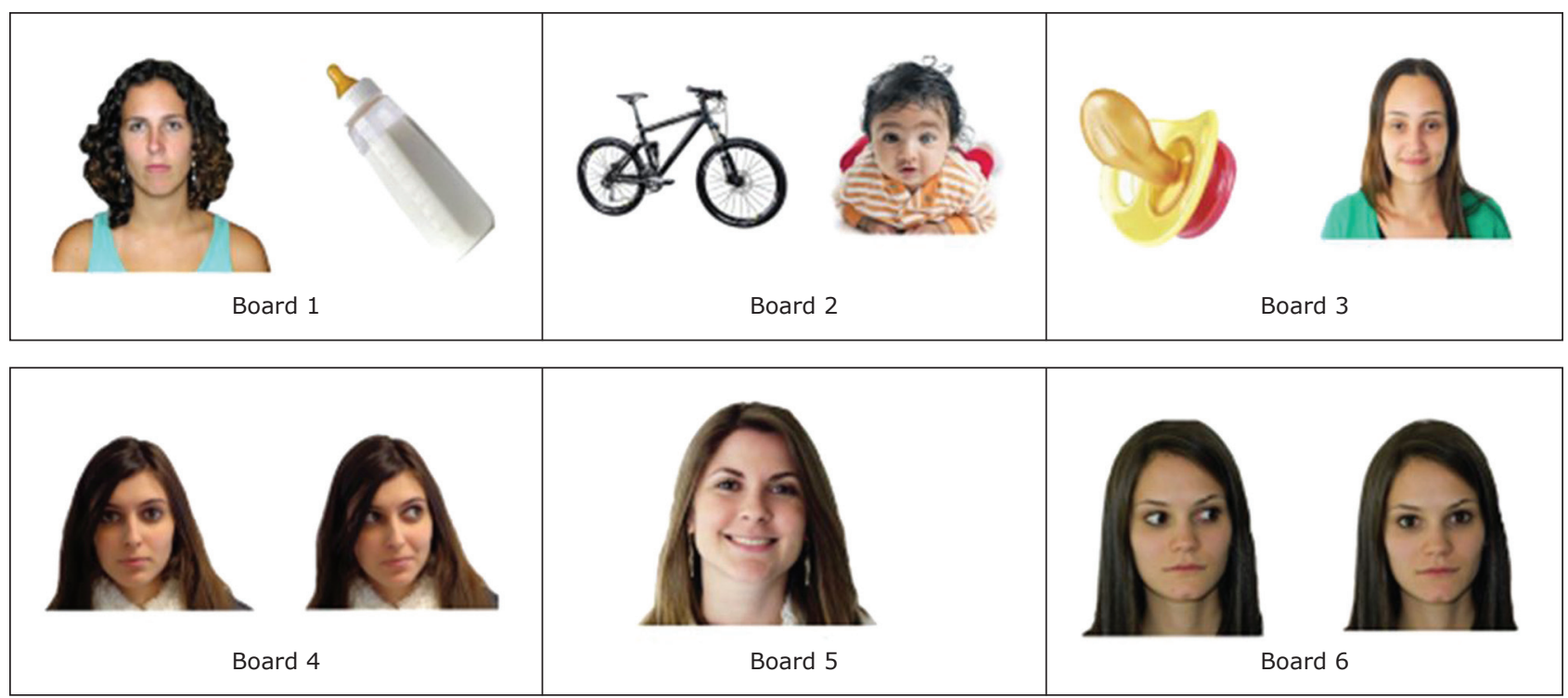

Figure 1 - Boards presented on the computer screen to the child 
pregnancy, $22.6 \%$ of the pregnant women smoked tobacco, and none reported drinking alcohol or using illicit drugs such as cocaine, crack or marijuana; $92.6 \%$ had a cesarean delivery and $54.8 \%$ received antenatal corticosteroids.

Mean gestational age at birth was $30.7 \pm 2.7$ weeks (24 to 35 weeks), mean birth weight was $1,362 \pm 363 \mathrm{~g}$ (655 to $2,000 \mathrm{~g}$ ), first-minute Apgar was $7.2 \pm 1.9$ (2 to 9), fifth-minute Apgar was 8.6 0.8 ( 7 to 10 ), and $32.3 \%$ of the preterm babies were small for gestational age.

During the neonatal unit hospitalization, preterm infants presented the following conditions: respiratory distress syndrome (48.4\%), patent ductus arteriosus $(16.7 \%)$, bronchopulmonary dysplasia (23.3\%), neonatal sepsis $(30.0 \%)$, peri-intraventricular hemorrhage $(26.7 \%)$, retinopathy of prematurity $(6.7 \%)$. None of the preterm babies developed periventricular leukomalacia while at the hospital.

Also during neonatal hospitalization, $36.7 \%$ of the preterm infants needed mechanical ventilation for
6.6 \pm 8.7 days (median 4.5, range $0-31$ ), and mean length of hospitalization was $46.8 \pm 28.5$ days (median 37 , range 13-113). After discharge from the neonatal unit, $26.7 \%$ of the preterm infants required a new hospitalization because of clinical complications, mainly respiratory disorders.

At the time of this study, the preterm babies presented 5.7 \pm 0.2 months of corrected age and $8.0 \pm 0.8$ months of chronological age.

\section{Eye-tracking test}

Visual scanning was performed in 31 preterm infants. At 6 months of corrected age, a similar percentage of preterm infants gazed at both social and non-social figures (boards 1, 2 and 3), at both direct and indirect looks (boards 4 and 6), and at eyes or mouth (board 5 ). The frequency ( $95 \%$ confidence interval) of preterm infants who gazed at the boards is presented in Figure 2.

Duration time of visualization of the two figures in each board is presented in Table 1. Preterm babies

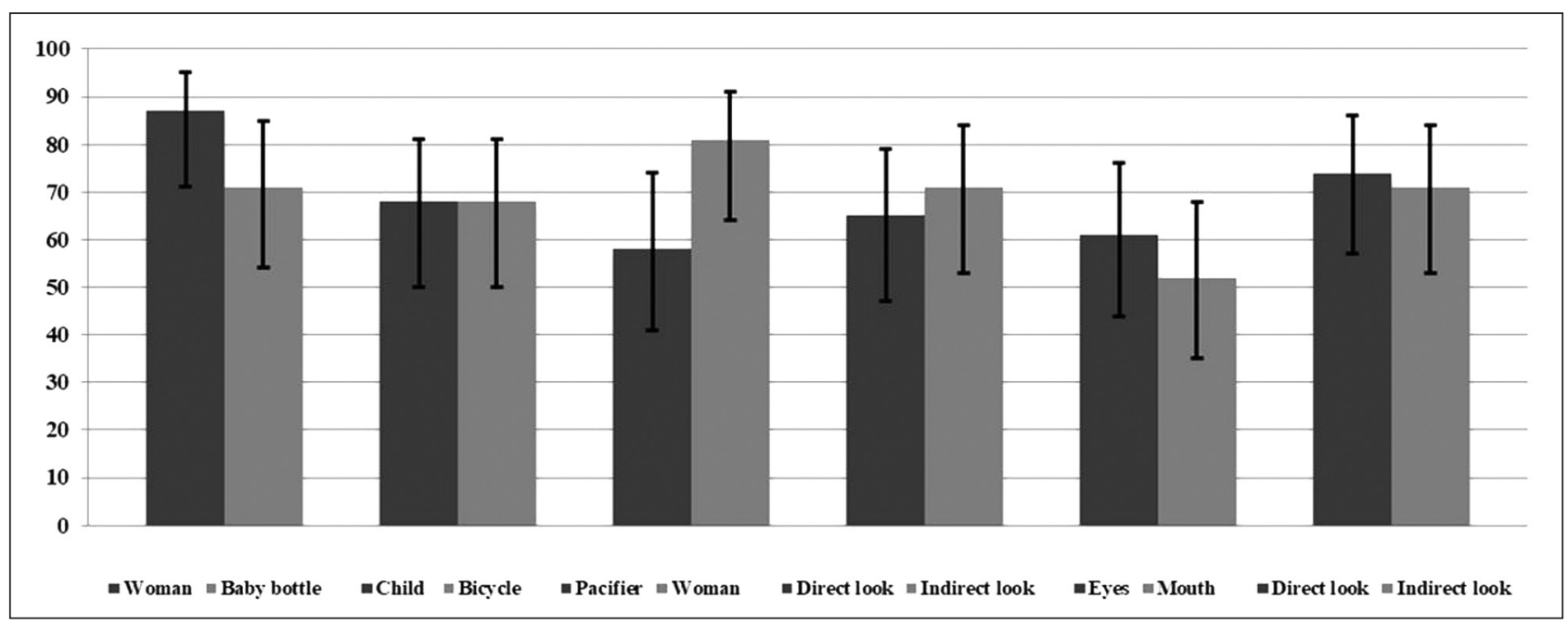

Figure 2 - Percentage (95\% confidence interval) of infants who gazed at each figure of the board (chi-square test: $p>0.05$ )

Table 1 - Percentage time of infant gazed at each picture

\begin{tabular}{|c|c|c|c|c|c|}
\hline Board & $\begin{array}{c}\text { Social/direct/ } \\
\text { eyes* }\end{array}$ & $\begin{array}{c}\text { Social/direct/ } \\
\text { eyes }^{+}\end{array}$ & $\begin{array}{c}\text { Nonsocial/ } \\
\text { indirect/mouth* }\end{array}$ & $\begin{array}{c}\text { Nonsocial/ } \\
\text { indirect/mouth }\end{array}$ & $\mathbf{p}$ \\
\hline 1 - Woman/Baby bottle & $19.5 \pm 20.4$ & $13.5(1.8-31.5)[0-65]$ & $1.1 \pm 1.4$ & $0(0-2)[0-4]$ & $<0.001$ \\
\hline 2 - Child/Bicycle & $10.3 \pm 16.4$ & $1(0-18)[0-53]$ & $4.4 \pm 10.0$ & $0(0-4)[0-46]$ & 0.047 \\
\hline 3 - Pacifier/Woman & $11.2 \pm 19.3$ & $2(0-9)[0-74]$ & $3.7 \pm 8.5$ & $0(0-6)[0-43]$ & 0.032 \\
\hline 4 - Direct look/Indirect look & $4.9 \pm 8.1$ & $0(0-9)[0-31]$ & $7.7 \pm 14.5$ & $2(0-11)[0-72]$ & 0.372 \\
\hline 5 - Eyes/Mouth & $3.0 \pm 6.1$ & $1(0-3)[0-29]$ & $3.3 \pm 10.2$ & $0(0-2)[0-56]$ & 0.452 \\
\hline 6 - Indirect look/Direct look & $8.3 \pm 11.2$ & $1(0-16)[0-39]$ & $4.4 \pm 9.1$ & $0(0-4)[0-37]$ & 0.057 \\
\hline
\end{tabular}

* Mean \pm standard deviation.

+ Median (1st quartile-3rd quartile) [minimum-maximum]. 
showed longer eye gaze toward social figures compared with non-social images (boards 1, 2 and 3), no matter the position of the social figure (left or right) or the social figure's age group (baby or adult). There were no significant differences in the percentage time of eye gaze between social figures with either a direct or indirect look (boards 4 and 6 ), or related to the part of the face, eyes or mouth (board 5).

\section{Modified Checklist for Autism in Toddlers (M-CHAT)}

None of the preterm infants screened positive for ASD signs at 18 months of corrected age, as evaluated with the M-CHAT. ${ }^{10}$

\section{Discussion}

Since their very first days of life, babies can follow social movements, a visual engagement mechanism that is extensively conserved in evolution. ${ }^{5,11}$ Full-term babies recognize the maternal figure from 3 months of age. ${ }^{12}$ Conversely, infants with an ASD diagnosis fail in social engagement and have reduced social interaction, face scanning and eye gaze and social elements, all of which are important ASD diagnostic markers. ${ }^{13}$ Conducting studies on the behavioral markers of ASD in early childhood is the way forward to overcome difficulties in diagnosis and enable new treatments and interventions. ${ }^{14}$

Preterm eye-tracking assessment could be an important tool to investigate ASD signs and other social ability impairments in this risk group, but few studies have been developed with preterm infants. Preterm babies present higher rates of developmental delays; therefore, specific assessments could help accurately determine areas of delay and establish diagnoses as well as interventions.

Eye-tracking studies involving preterm infants born before 32 weeks of gestational age at 2 and 4 months of corrected age have shown a different screening pattern when compared with term children. Although preterm infants showed inferior screening results at 2 months of corrected age in comparison with fullterm children, an improvement and increase of the preterm eye gaze was noticed at 4 months of corrected age. ${ }^{15}$ At 6 and 10 months of corrected age, preterm babies showed a proper percentage of scanning, but with a shorter duration of eye gaze on social figures when compared with full-term children (1.16 vs. 1.5 seconds). ${ }^{16}$ These results with preterm babies are similar to our findings, showing the ability of preterm infants to gaze at 6 months of corrected age, although with a shorter fixation time when compared with term children. Atypical facial screening or decreased visual sensitivity were also described in preterm infants with periventricular injuries, ${ }^{17}$ indicating that sequelae of clinical intercurrences during the neonatal period could influence these results.

In our study, the preterm infants evaluated at 6 months of corrected age showed adequate and similar percentages of gaze at social and non-social figures. Although data for term children are well known, ${ }^{6}$ our results with premature infants are relevant as they demonstrate that this population can also be evaluated at this age using the same tool.

Visual scanning studies involving term babies aged 2 to 24 months of age demonstrate different patterns of visual preference and different gaze fixation times between typical children and a group later diagnosed with ASD. Typical children presented visual preference for social figures and eyes at 2-6 months of age, with a plateau in relation to gaze fixation time at 6-24 months. Conversely, children with ASD initially presented preference and visual fixation time similar to those of typical children, but showing a decline from 2 months of age. At 6 months of age, the difference between the two groups was statistically significant, and the decline showed a strong relationship with social impairments and a subsequent diagnosis of ASD. ${ }^{11}$ Thus, visual preference for social or non-social figures may be a valuable tool in the evaluation of suspicious signs of ASD, especially in at-risk populations and in those with several developmental delays such as preterm infants.

In our study, the assessment of visual preferences in preterm infants at 6 months of corrected age pointed to favor toward social figures over non-social images. None of the preterm infants in our sample screened positive for signs of ASD at 18 months of age as assessed using the M-CHAT, confirming the same visual preference in our sample of preterm infants as in typical full-term infants. ${ }^{6,11}$ A similar result was obtained in a study comparing preterm, full-term, and full-term infants diagnosed with ASD. Among the preterm infants, those who did not show a preference for social stimuli also presented social difficulties and a subsequent diagnosis of ASD. ${ }^{7}$

Contrary to results obtained by other authors, ${ }^{13}$ no preference for social figures with a direct look vs. those with an indirect look could be verified in our study, nor even a preference for the eyes instead of the mouth. A study involving preterm infants born with different gestational ages demonstrated that they had subtle delays in neuropsychological and behavioral functions at 3 years of age in relation to term-born controls. Neurobiological immaturity 
remained a preponderant influence in the results among preschoolers, measured by performance in terms of verbal, non-verbal, fine motor, visual motor, visual attention and functional communication. ${ }^{18}$ It is possible that preterm infants at 6 months of corrected age still have a different visual preference pattern in relation to full-term infants in favor of direct eye or eye region of social figures. Another hypothesis is that the reduced number of participants in this study did not allow the detection of subtle differences in visual preferences. Studies involving larger samples, with follow-up over the months, will be necessary to better understand these results.

Even though this is a preliminary study, the fact that visual screening of preterm infants at 6 months of corrected age is possible, and that they have a visual preference pattern similar to that of typical fullterm children, provides important indications that eye tracking is a useful instrument for use in the preterm population and may aid in the evaluation of social skills impairments.

As study limitations, it is important to mention the small convenience sample used and the lack of a control group, which prevents definitive conclusions. Also, term infants were not included in this study, as it was performed in a referral outpatient clinic for premature babies. Longitudinal studies may provide relevant data for a better understanding of visual scanning patterns in preterm infants. Finally, in addition to M-CHAT, complementary instruments based on direct observation of the child could also have been used to evaluate early signs of ASD.

In conclusion, according to our results, at 6 months of corrected age, children born prematurely have visual fixation ability in eye-tracking tests and show a preference for social figures to the detriment of nonsocial ones. This findings suggest that it is possible to use eye tracking in this population, at this age, to evaluate visual preferences, which in turn can be important to identify early signs of ASD.

\section{Disclosure}

No conflicts of interest declared concerning the publication of this article.

\section{References}

1. Pinto-Martins JA, Levy SE, Feldman JF, Lorenz JM, Paneth $\mathrm{N}$, Whitaker $\mathrm{AH}$. Prevalence on autism spectrum disorder in adolescents born weighing $<2000$ grams. Pediatrics. 2011;128:883-93.

2. Saigal S, Doyle LW. An overview of mortality and sequelae of preterm birth from infancy to adulthood. Lancet. 2008;371:261-9.

3. Johnson S, Hollis C, Kochhar P, Hennessy E, Wake D, Marlow N. Autism spectrum disorders in extremely preterm children. J Pediatr. 2010;156:525-31.

4. Hofheimer J, Scheinkpf SJ, Eyler LT. Autism risk in very preterm infants: new answers, more questions. J Pediatr. 2014;164:6-8.

5. Johnson $\mathrm{MH}$, Dziurawiec S, Ellis H, Morton J. Newborns' preferential tracking of face-like stimuli and its subsequent decline. Cognition. 1991;40:1-19.

6. Jones $\mathrm{W}, \mathrm{Klin} \mathrm{A}$. Attention to eyes is present but in decline in 2-6-month-old infants later diagnosed with autism. Nature. 2013;504:427-31.

7. Sekiwaga-Hosozawa M, Tanaka K, Shimizui T, Nakano T, Kitazana S. A group of very preterm children characterized by atypical gaze patterns. Brain Dev. 2017;39:218-24.

8. Olsen IE, Sue A, Groveman SA, Lawson ML, Clark RH, Zemel CR. New intrauterine growth curves based on United States data. Pediatrics. 2010;125:214-24.

9. Robins DL, Fein D, Barton ML, Green JA. The Modified Checklist for Autism in Toddlers: an initial study investigating the early detection of autism and pervasive developmental disorders. ] Autism Dev Disord. 2001;31:131-44.

10. Losapio MF, Pondé MP. Tradução para o português da escala M-CHAT para rastreamento precoce de autismo. Braz J Psychiatry. 2008;33:221-9.

11. Klin A, Shultz S, Jones W. Social visual engagement in infants and toddlers with autism: early developmental transitions and a model of pathogenesis. Neurosci Biobehav Rev. 2015;50:189203.

12. Mash $\mathrm{C}$, Bornstein $\mathrm{MH}$, Arterberry ME. Brain dynamics in young infants' recognition of faces: EEG oscillatory activity in response to mother and stranger. Neuroreport. 2013;24:359-63.

13. Klin A, Klaiman C, Jones W. Reducing age of autism diagnosis: developmental social neuroscience meets public health challenge. Rev Neurol. 2015;60:S3-11.

14. Merin N, Young GS, Ozonoff S, Rogers SJ. Visual fixation patterns during reciprocal social interaction distinguish a subgroup of 6-month-old infants at-risk for autism from comparison infants. J Autism Dev Disord. 2007;37:108-21.

15. Strand-Brodd K, Ewald U, Grönqvist H, Holmström G, Strömberg B, Erik Grönqvist $E$, et al. Development of smooth pursuit eye movements in very preterm infants: 1 . General aspects. Acta Paediatrica. 2011;100:983-91.

16. Telford EJ, Fletcher-Watson S, Gillespie-Smith $K$, Pataky R, Sparrow S, Murray IC, et al. Preterm birth is associated with atypical social orienting in infancy detected using eye tracking. J Child Psychol Psychiatry. 2016;57:861-86.

17. Pavlova MA. Biological motion processing as a hallmark of social cognition. Cereb Cortex. 2012;22:981-95.

18. Elsabbagh M, Holmboe K, Gliga T, Mercure E, Hudry K, Charman $\mathrm{T}$, et al. Social and attention factors during infancy and the later emergence of autism characteristics. Prog Brain Res. 2011;189:195-207.

\section{Correspondence:}

Vivian R. G. Lederman

Alameda Franca, 660

01422-000 - São Paulo, SP - Brazil

Tel.: +55 (11) 32539247

E-mail: vlederman26@gmail.com 